\title{
DAS PERSPECTIVAS TÉCNICAS E SUPRA-ORGÂNICAS ÀS \\ REPRESENTACIONAIS: BREVES REFLEXÕES SOBRE AS ABORDAGENS GEOGRÁFICAS ACERCA DA CULTURA
}

\author{
Diego Salomão Candido de O. Salvador \\ Mestrando em Geografia na UFRN. Bolsista da CAPES \\ diegolisse@yahoo.com.br
}

\begin{abstract}
RESUMO
Até meados do século XX, a cultura foi compreendida no âmbito dos estudos geográficos sob pontos de vista técnicos e supra-orgânicos. Devido à intensa modernização das técnicas humanas, as quais se tornaram uniformes, as visões técnicas e supra-orgânicas da cultura tornaram-se, por volta da década de 1940, impertinentes à realidade mundial. Em função disso, a partir da década de 1970, o entendimento da cultura no bojo da ciência geográfica passa por um processo de renovação. A cultura passa a ser compreendida sob a perspectiva das representações, dos significados e dos sentidos. Os espaços não são mais constituídos apenas por cores, materialidades e funcionalidades, mas também por cheiros, representatividades, significações etc. O cotidiano e as percepções dos homens são elementos importantes para analisarmos e compreendermos os espaços. Desse modo, podemos afirmar que o objetivo deste trabalho é refletir sobre a evolução das abordagens geográficas acerca da cultura. Para isso, colocamos em tela breves reflexões sobre a Geografia Cultural Clássica, a Geografia Cultural Renovada e o conceito de paisagem. Essas reflexões são decorrentes de uma revisão bibliográfica feita por nós em alguns livros e textos que versam sobre as abordagens culturais na Geografia. Desse modo, declaramos ser, na atualidade, imprescindível refletir acerca das culturas, as quais se encontram completamente relacionadas às premissas do horizonte geográfico humanista.
\end{abstract}

PALAVRAS-CHAVE: Geografia. Cultura. Renovação.

\section{DES PERPECTIVES TECHNIQUES ET SUR-ORGANIQUES JUSQU'ÀS REPRÉSENTATIVES: BRÈVES RÉFLEXIONS SUR LES APPROCHES GÉOGRAPHIQUES SUR LA CULTURE}

\begin{abstract}
RÉSUMÉ
Jusqu'à la mi-siècle $\mathrm{XX}$, la culture était comprend dans un sens des études géographiques sur points de vue techniques et sur-organiques. À cause de la intense modernization des techniques humaines qui se sont devenues uniformes, les visons techniques et surorganiques de la culture se sont devenues, dans les années quarante, inadaptées à la réalité mondiale. C'est pour ça que, dans les années soixante-dix, la compréhension de la culture pour la science géographique passe par un procès de renouvellement. La culture, alors, est comprend sur la perspective des représentations, des significations et des sensations. Les espaces ne sont plus constitués seulement de couleurs, choses matérielles et fonctionnelles, mais encore pour odeurs, représentations, significations, etc. Le quotidien et les perceptions des hommes sont éléments importants pour analiser et comprendre les espaces. Ainsi, nous pouvons afirmer que l'objectif de cet travail est réfléchir sur l'évolution des approches géographiques sur la culture. Pour celui, nous faisons brèves réflexions sur la Géographie Culturelle Classique, la Géographie Culturelle Renovée et le concept de paysage. Cettes réflexions sont résultat d'une révision bibliographique réalisé pour nous en


quelques livres et textes qui parlent sur les approches culturelles en la Géographie. Ainsi, nous déclarons qui est, actuellement, indispensable réfléchir sur les cultures qui sont complètement en relation avec les concepts du horizon géographique humain.

MOTS-CLÉ: Géographie. Culture. Renouvellement. 


\section{DAS PERSPECTIVAS TÉCNICAS E SUPRA-ORGÂNICAS ÀS REPRESENTACIONAIS: BREVES REFLEXÕES SOBRE AS ABORDAGENS GEOGRÁFICAS ACERCA DA CULTURA}

\section{OS INTERESSES GEOGRÁFICOS ACERCA DA CULTURA: BREVES PALAVRAS INTRODUTÓRIAS}

Os interesses geográficos sobre os diversos povos e suas culturas não são recentes. Claval (1999a) afirma que esses interesses existem desde Heródoto. Falando-nos sobre a história do pensamento geográfico, Andrade (1987) declara que desde os tempos primitivos diversos povos, como os romanos, árabes, italianos, dentre outros, realizavam viagens nas quais buscavam manter contatos econômicos e culturais com diversos outros povos. Dessa maneira, não podemos afirmar que a inter-relação entre Geografia e Cultura seja recente, mas sim bastante antiga.

A cultura necessita ser compreendida como um imenso campo de estudo das ciências humanas. Cada área de conhecimento busca abordar esse campo de maneira específica. Os geógrafos, quando procuram realizar análises culturais, devem não dissociar “[...] os grupos dos territórios que organizaram e onde vivem; a estrutura e a extensão dos espaços de intercomunicação, a maneira como os grupos vencem o obstáculo da distância e algumas vezes o reforçam [...]” (CLAVAL, 1999a, p. 11).

As culturas não são realidades imutáveis. Elas são historicamente (re)construídas pelos seres humanos. Estes não vivenciam as culturas de maneira passiva. Pelo contrário, os homens recebem as culturas como heranças, passando a interiorizá-las, a (re)inventá-las, a atribuir-lhes novos significados, a criticá-las ou até mesmo a rejeitá-las.

Devemos ter a consciência de que a cultura não é meramente constituída de realidades marcadas pela materialidade espacial. A cultura carrega em si uma grandiosa carga de signos e significados que são historicamente escritos, dominados e verbalizados. Nessa perspectiva, Claval (Ibid., p. 14) defende que a cultura

carrega-se, assim, de uma dimensão simbólica. Ao serem repetidos em público, certos gestos assumem novas significações. Transformam-se em rituais e criam, para aqueles que os praticam ou que os assistem, um sentimento de comunidade compartilhada (destaque do autor).

Também devemos saber que a cultura apresenta-se como um fator essencial de diferenciação social. Dificilmente em uma sociedade todos os indivíduos compartilham as mesmas heranças culturais. O que existe nas sociedades mundiais atuais são modelos culturais aceitos e reconhecidos pela maioria dos indivíduos. Esses modelos podem ser chamados de dominantes. Contudo, não podemos acreditar que não existam contraculturas, isto é, modelos culturais que são dissidentes dos modelos dominantes.

A Geografia na atualidade é marcada pelo horizonte de estudos humanistas. Gomes (1996) nos ensina que o horizonte geográfico humanista fundamenta-se nas análises espaciais 
sempre atentas para as culturas humanas. Com o mesmo raciocínio, Claval (1999a, p. 20) declara que "a geografia humana encerra [...] desde as suas primeiras etapas, um componente cultural [...]”. Desse modo, podemos defender que os geógrafos humanistas não devem, em hipótese alguma, esquecerem-se da dimensão cultural em seus estudos e/ou análises acerca dos espaços geográficos. Geografia e cultura, na atualidade, devem ser palavras indissociáveis.

Este trabalho tem o objetivo de refletir sobre a evolução das abordagens geográficas acerca da cultura. Não temos a pretensão de desencadear aqui reflexões aprofundadas. Pelo contrário, nossas reflexões são fruto de uma revisão bibliográfica feita por nós apenas em alguns textos que versam sobre a Geografia Cultural. Com isso, deve-se saber que nossas reflexões são breves, necessitando ser fomentadas através da realização de outras leituras. Visando atingir nosso objetivo, sistematizamos o trabalho da seguinte maneira: primeiro, vamos tecer breves reflexões sobre a Geografia Cultural Clássica; após isso, as reflexões serão direcionadas para a chamada Geografia Cultural Renovada; e, por fim, colocaremos em tela algumas discussões sobre o conceito de paisagem.

Finalizando nossas palavras introdutórias, destacamos uma discussão que existe no âmbito da Geografia Cultural Renovada. Essa discussão consiste em considerar a Geografia Cultural como um subcampo da ciência geográfica ou não. Para Corrêa e Rosendahl (2003, p. 09), assim como para outros geógrafos, “a geografia cultural é um significativo subcampo da geografia, que a partir da Europa difundiu-se e já tem um século de existência”. Já para Claval (2003, p. 147), “[...] todos os fatos geográficos são de natureza cultural”. Com isso, o geógrafo francês não considera a Geografia Cultural como um subcampo da ciência geográfica, preferindo "[...] falar de abordagem cultural na geografia e não de geografia cultural”.

Essa discussão, a nosso ver, explicita um fato que permeia a história do pensamento geográfico: a necessidade de compartimentalizar a Geografia em várias especializações. Andrade (1987) nos ensina que a ampliação dos conhecimentos geográficos na primeira metade do século XX levou os geógrafos a buscarem especializações dentro da sua ciência. Essa necessidade fez com que eles se dividissem, a partir de então, em aqueles que faziam Geografia Física e aqueles que faziam Geografia Humana.

Posteriormente, essa divisão foi considerada pequena e buscou-se ampliá-la. Numerosas subdivisões surgiram dentro da ciência geográfica, colocando em tela geógrafos que optaram por ser geomorfólogos, hidrólogos, climatólogos, especialistas em Geografia Econômica, Política, Agrária, Social, dentre muitas outras. Essas subdivisões transformaram "[...] praticamente cada capítulo da Geografia em especialização, como se os fatos estudados não estivessem interligados” (Ibid., p. 17-18).

Seguindo as perspectivas atuais do horizonte geográfico humanista, que procura trabalhar com as interfaces e não com as compartimentalizações, declaramos que acima das especializações existe certa unidade no conhecimento geográfico. As leituras e interpretações que fazemos no momento nos levam a defender que, se prosseguirmos esfacelando a Geografia em subcampos, estaremos contribuindo para o não aprofundamento das compreensões acerca do seu objeto de estudo: o espaço geográfico. Nossos estudos e nossas reflexões devem versar sobre Geografia, na essência da palavra. É redundante falarmos em "Geografia Social”, “Geografia Humana”, “Geografia Cultural”, 
como se essas expressões representassem áreas de conhecimentos que existem dentro ou, até mesmo, separadas da Geografia, ciência social.

Por isso, afirmamos acreditar, de acordo com as concepções do horizonte geográfico humanista, que todos os fatos geográficos são de ordem cultural. Nossa postura vai de encontro à de Claval (2003), quando prefere falar em abordagem cultural na Geografia. Portanto, quando utilizarmos a expressão Geografia Cultural no presente trabalho, estaremos nos referindo às abordagens geográficas acerca da cultura.

\section{GEOGRAFIA CULTURAL CLÁSSICA: A CULTURA SOB OS PONTOS DE VISTA TÉCNICO E SUPRA-ORGÂNICO}

O primeiro geógrafo a desenvolver reflexões geográficas acerca da cultura foi Ratzel. Dentro de suas concepções Antropogeográficas, que buscavam inter-relacionar homem e natureza, esse geógrafo alemão utilizou-se do termo Culturgeographie para expressar o seu entendimento sobre cultura. Para ele, a cultura seria o conjunto de utensílios e técnicas utilizadas pelos homens nas suas ações em relação ao meio. As palavras de Claval (1999a, p. 22) explicitam bem o entendimento de Ratzel acerca da cultura: “[...] sobretudo analisada sob os aspectos materiais, como um conjunto de artefatos utilizados pelos homens em sua relação com o espaço. As idéias que a subentendem e a linguagem que a exprimem não são [...] evocadas”.

Outro nome de destaque no contexto das primeiras abordagens científicas interrelacionadoras da Geografia e da Cultura foi o do geógrafo francês Paul Vidal de La Blache. Para ele, a cultura, a exemplo das concepções de Ratzel, compreenderia os instrumentos utilizados pelos seres humanos para transformarem e/ou modelarem as paisagens. Esses instrumentos, segundo La Blache, não poderiam ser analisados e compreendidos de maneira dissociada do conceito de gênero de vida. Os gêneros de vida seriam as diferentes maneiras que os homens têm de agir frente à natureza, buscando dominá-la. Desse modo, a cultura representaria o conjunto de técnicas e instrumentos utilizados pelos homens em seus gêneros de vida. Mais uma vez nos utilizamos das palavras de Claval (Ibid., p. 35), agora para explicitar o entendimento de cultura para La Blache:

\footnotetext{
a cultura é para Vidal de La Blache e seus alunos, como para Ratzel e os geógrafos alemães, aquilo que se interpõe entre o homem e o meio e humaniza as paisagens. Mas é também uma estrutura geralmente estável de comportamentos que interessa descrever e explicar (destaques do autor).
}

Apesar das considerações de Ratzel e La Blache terem grande importância para o desencadeamento das abordagens culturais na Geografia, devemos afirmar que o grande expoente dos estudos da chamada Geografia Cultural Clássica é o geógrafo norteamericano Carl O. Sauer, fundador e nome de peso da Escola de Berkeley.

De acordo com Sauer, os estudos geográficos sobre as culturas deveriam atentar para as paisagens culturais, sobretudo sob um ponto de vista morfológico e histórico. Claval (Ibid., 
p. 31) afirma que "para fazer geografia cultural na maneira de Carl O. Sauer, convém ter uma sólida formação naturalista - ao menos de botânico”.

A Geografia Cultural saueriana se alicerçava na diferenciação da Terra em áreas, na observação morfológica da paisagem, baseando-se em primeiro lugar nos aspectos físicos, e no método historicista, privilegiando os acontecimentos pretéritos. O próprio Sauer (2003, p. 25) nos diz qual é a sua concepção sobre a Geografia Cultural:

a geografia cultural implica [...] um programa que está integrado com o objetivo geral da geografia, isto é, um entendimento da diferenciação da Terra em áreas. Continua sendo, em grande parte, observação de campo baseada na técnica de análise morfológica desenvolvida em primeiro lugar na geografia física. Seu método é evolutivo, especificamente histórico até onde a documentação permite e, por conseguinte, trata de determinar as sucessões de cultura que ocorreram numa área.

Para Sauer, os estudos culturais na Geografia deveriam ser calcados em cinco temas: cultura; história da cultura; paisagem cultural; área cultural; e ecologia cultural. Esses temas foram bastante trabalhados nos estudos de Sauer e de seus discípulos. Uma abordagem detalhada sobre os cinco temas da Geografia Cultural saueriana pode ser encontrada no trabalho de Wagner e Mikesell (2003), discípulos de Sauer.

A cultura para Sauer seria, inicialmente, também o conjunto de instrumentos e de artefatos que permitem aos homens agirem frente à natureza, a qual seria exterior aos humanos. Sauer defendia que as transformações da natureza, desencadeadas pelos homens, não são inocentes, ocasionando, por vezes, degradações graves. Devido a isso, Sauer não gostava da sociedade americana de seu tempo, em função de ela agir brutalmente com relação aos aspectos naturais, tolerando e favorecendo desperdícios (CLAVAL, 1999b).

Nas décadas de 1920-30, Sauer passa a ter contatos com antropólogos americanos, com destaque para Alfred Kroeber e Robert Lowie. Esses contatos influenciam as concepções de Sauer, fazendo com que ele passe a considerar a cultura sob um ponto de vista supraorgânico.

A teoria da cultura como entidade supra-orgânica, aceita e trabalhada por Sauer, foi esboçada por A. Kroeber e R. Lowie nos primeiros anos do século XX, sendo elaborada, posteriormente, por Leslie White (DUNCAN, 2003). A cultura como uma entidade supraorgânica seria um processo sui generis, isto é, que se auto-determinava e determinaria as ações humanas. Sob o ponto de vista supra-orgânico, os homens seriam mensageiros passivos da cultura, não tendo a possibilidade de alterá-la e/ou contestá-la. Duncan (Ibid., p. 72) afirma que, de acordo com a visão supra-orgânica, “[...] a cultura é algo separado dos indivíduos, ela precisa dos indivíduos [apenas] para se realizar”.

Em meados do século XX, ocorre, em âmbito global, um intenso processo de mecanização e modernização das técnicas e instrumentos humanos, tornando-os uniformes. Essa uniformização das técnicas e instrumentos humanos fez com que os estudos geográficos acerca da cultura, calcados no ponto de vista técnico, perdessem sentido frente ao novo contexto. Em outras palavras, diz-se que a cultura como o conjunto de técnicas e instrumentos humanos perde a sua pertinência frente à nova realidade mundial. 
Além disso, por volta da década de 1940, desenvolve-se na Antropologia americana o pensamento de que não seria mais interessante estudar a cultura como uma entidade supraorgânica, tendo os indivíduos como simples recipientes e mensageiros culturais passivos.

Nesse contexto, a cultura como uma entidade supra-orgânica passa a ser vista como um erro ontológico, um caso de antropomorfismo. É essa a opinião de Duncan (2003, p. 89): "minha posição é a de que a separação do indivíduo da cultura é um erro ontológico. É um caso de antropomorfismo - de reificar um construto mental e atribuir-lhe autodireção e poder sobre os homens - que é puramente fictício”.

Desse modo, os estudos culturais na perspectiva da Geografia perderam suas pertinências diante do novo contexto mundial. Esses estudos foram adormecidos, entre as décadas de 1940-70, e tudo indicava que a Geografia Cultural caminhava para o desaparecimento.

\section{GEOGRAFIA CULTURAL RENOVADA: A CULTURA SOB O PONTO DE VISTA DAS REPRESENTAÇÕES}

O desaparecimento da Geografia Cultural que parecia um fato certo para acontecer não se realizou. O que ocorreu, a partir da década de 1970, foi um processo de renovação dos estudos.

Essa renovação se dá de maneira indissociável à intensificação do horizonte geográfico humanista. Os estudos da chamada Geografia Humanista atentam para o espaço vivido, perpassado pelos sentidos e pelos significados escritos pelos seres humanos historicamente. Nessa perspectiva, os estudos geográficos humanistas buscam conhecer e compreender as diversas culturas humanas (GOMES, 1996).

De acordo com Claval (1999a, 1999b), os estudos da Geografia Cultural Renovada apresentam alguns traços importantes que devem ser colocados em tela: os espaços não são perpassados apenas por formas, cores e funcionalidades racionais e econômicas, mas também por sentidos e significados escritos historicamente por aqueles que os vivenciam; o conhecimento e a compreensão sobre as percepções do espaço por parte dos humanos é fator imprescindível; valoriza-se não somente aquilo que é racional, mas também o romântico, isto é, atenta-se para as razões e para as emoções.

A cultura, antes analisada sob perspectivas técnicas e supra-orgânicas, passa a ser considerada sob o ponto de vista das representações, dos sentidos e significados atribuídos pelos homens aos espaços vividos. As palavras de Claval (1999a, p. 50) explicitam melhor o entendimento atual da cultura no âmbito da Geografia:

o contexto [atual] obriga [...] os geógrafos a não negligenciarem as dimensões culturais dos fatos que observam. Ele orienta sua curiosidade numa nova direção: as técnicas tornaram-se demasiadamente uniformes para deter a atenção; são as representações, negligenciadas até então, que merecem ser estudadas (destaque do autor). 
Os estudos desenvolvidos no âmbito dessa renovação procuram não desconsiderar e/ou negligenciar o legado clássico de Ratzel, La Blache e Sauer. Pelo contrário, considera-se importante compreender esse legado para que se busque ultrapassá-lo e/ou ampliá-lo. Segundo Corrêa e Rosendahl (2003), o processo de renovação da Geografia Cultural é marcado por diversas influências, como o legado clássico dos geógrafos citados, a influência das filosofias do significado (como a fenomenologia) e do denominado materialismo cultural proposto por Raymond Williams.

Após as breves considerações sobre o processo de renovação da Geografia Cultural, podemos declarar que a cultura na atualidade pode ser compreendida como

[...] a soma dos comportamentos, dos saberes, das técnicas, dos conhecimentos e dos valores acumulados pelos indivíduos durante suas vidas e, em uma outra escala, pelo conjunto dos grupos de que fazem parte. A cultura é herança transmitida de uma geração a outra. Ela tem suas raízes num passado longínquo, que mergulha no território onde seus mortos são enterrados e onde seus deuses se manifestaram. Não é portanto um conjunto fechado e imutável de técnicas e de comportamentos (CLAVAL, 1999a, p. 63).

Por fim, afirma-se que se deve ter em mente que a Geografia Cultural Renovada desencadeia-se sob uma perspectiva bastante ampla. Atenta-se para o novo e o velho, para o social e o natural, para o urbano e o rural, para as culturas hegemônicas e as hegemonizadas, para o real e o ideal etc. Alguns nomes de estudiosos podem ser destacados como partícipes desse processo de renovação das abordagens geográficas culturais. No cenário mundial: D. Cosgrove; J. Duncan; R. Williams; Yi-Fu Tuan; A. Frémont; J. Bonnemaison; A. Berque; P. Claval; dentre outros. No cenário nacional: R. L. Corrêa; Z. Rosendahl; dentre outros.

\section{PAISAGEM: DO ENTENDIMENTO MORFOLÓGICO AO HERMENÊUTICO}

O estudo da paisagem, segundo Claval (Ibid., p. 318), “[...] constitui um dos capítulos fundamentais da geografia cultural - aquele que estuda a mediação pela qual os grupos humanos asseguram sua possessão sobre o espaço e submetem-se a sua influência [...]”.

O interesse pela paisagem caracterizou os estudos geográficos sauerianos. Aliás, vale dizer que para Sauer o objeto de estudo da Geografia Cultural era a paisagem. Ele defendia a existência de dois tipos de paisagem: a natural (sendo a paisagem primeira) e a cultural (decorrente das modificações desencadeadas pelos homens na natureza). Desse modo, pode-se afirmar que Sauer compartimentalizava cultura e natureza, ou melhor dizendo, homem e meio.

A paisagem cultural, para Sauer, deve ser analisada e compreendida historicamente, por meio das transformações realizadas pelos homens em sua morfologia (em seus aspectos físicos). O entendimento que Sauer tem sobre a paisagem cultural fica explícito a partir das seguintes palavras: “a paisagem cultural é formada a partir da paisagem natural pelo grupo cultural. O grupo é a força ativa, a área natural é o meio no qual o grupo atua e a paisagem cultural é o resultado” (SAUER, 1998, p. 68). 
A paisagem analisada sob o ponto de vista morfológico, da maneira como propõe Sauer, é compreendida como aquilo que os nossos olhos alcançam. Com isso, percebe-se que os elementos morfológicos da paisagem são, sobretudo, os naturais. Dessa maneira, podemos declarar que as concepções de Sauer acerca da paisagem privilegiam, predominantemente, os seus aspectos estéticos. A paisagem é valorizada por si mesma, isto é, simplesmente pela sua imagem.

Com o processo de renovação dos estudos da Geografia Cultural, o entendimento da paisagem é transformado. Não se pode mais compreendê-la meramente a partir dos seus elementos naturais. A paisagem, além de suas formas, cores e funcionalidades, também é marcada por cheiros, significados, representações, valores, pensamentos, idéias etc. A paisagem é um texto construído historicamente que deve ser lido e interpretado.

Desse modo, consideramos a paisagem como aquilo que os sentidos alcançam, não devendo ser vista e compreendida, em hipótese alguma, como um simples artefato físico impessoalizado. A paisagem tem dimensões que perpassam pelos sentidos humanos, isto é, pelas percepções, sendo marcada por relações sociais dadas ao longo do tempo (COSGROVE, 1999 e 1998 ; CORRÊA e ROSENDAHL, 2003, 2000 e 1998).

Segundo Monbeig (2005, p. 118), a paisagem é uma construção humana, um reflexo da sociedade. "Ao lado das forças naturais como a chuva, o vento, o mar, o vulcão, aparece outra força natural, o homem. O homem, que, com seus utensílios, a inteligência que lhe guia as mãos, é capaz de transformar a tal ponto o meio natural [...]”. Desse modo, “[...] aquilo que tomamos atualmente por uma paisagem obra da natureza, não é senão o cenário construído por ele [pelo homem]”.

Sendo a paisagem uma construção humana, dada historicamente, é, pois, tarefa do geógrafo

\begin{abstract}
ver como a paisagem é o reflexo da civilização [...]; é um trabalho de análise que ele [o geógrafo] precisa fazer para distinguir o que provém do solo, do clima e também da técnica agrícola, da organização social. A análise da paisagem apresenta-se como jogo de quebra-cabeça; mas, enquanto o jogo se torna fastidioso, é apaixonante o estudo da paisagem: apaixonante porque nos põe em contato com a humilde tarefa quotidiana e milenar das sociedades humanas; ela mostra o homem lutando sem cessar para aperfeiçoar-se. E no momento preciso em que nos sentiríamos inclinados ao desespero, dá coragem e confiança nos destinos da humanidade (Ibid., p. 127).
\end{abstract}

Santos (1999) tece algumas reflexões sobre a paisagem, tendo como principal objetivo mostrar que paisagem e espaço não são sinônimos. Para ele, a paisagem é, “a rigor, [...] apenas a porção da configuração territorial que é possível abarcar com a visão” (Ibid., p. 83). Ela é um sistema material, relativamente imutável. "[...] a paisagem permite apenas supor um passado. [...] A paisagem é história congelada, mas participa da história viva” (Ibid., p. 86).

Não podemos considerar a paisagem como sendo meramente aquilo que se vê. Tomando de empréstimo as concepções de Monbeig (2005), podemos afirmar que a paisagem é 
aquilo que se vê e se sente, enfim, aquilo que se vive. A paisagem não é apenas história congelada, mas também história em movimento. Ela guarda em si acontecimentos pretéritos e revela fatos que acontecem no presente. O próprio Santos (1999) afirma que a paisagem participa da história viva. Em suma, a paisagem é um texto constituído por elementos da natureza que são historicamente artificializados pelas ações humanas. Essas artificializações não nos permite afirmar que a paisagem seja um mero artefato físico, isenta de ações e vivências humanas.

Com esse entendimento, podemos declarar que a paisagem é multidimensional. Algumas de suas múltiplas dimensões são citadas por Corrêa e Rosendahl (1998, p.08) no momento em que declaram que a paisagem

[...] apresenta simultaneamente várias dimensões que cada matriz epistemológica privilegia. Ela tem uma dimensão morfológica, ou seja, é um conjunto de formas criadas pela natureza e pela ação humana, e uma dimensão funcional, isto é, apresenta relações entre as suas diversas partes. Produto da ação humana ao longo do tempo, a paisagem apresenta uma dimensão histórica. Na medida em que uma mesma paisagem ocorre em certa área da superfície terrestre, apresenta uma dimensão espacial. Mas a paisagem é portadora de significado, expressando valores, crenças, mitos e utopias: tem assim uma dimensão simbólica.

Refletindo sobre as dimensões da paisagem, Cosgrove (1998, p. 100) destaca que “[...] a paisagem lembra-nos que a Geografia está em toda parte, que é uma fonte constante de beleza e feiúra, de acertos e erros, de alegria e sofrimento, tanto quanto é de ganho e perda”.

A paisagem é extremamente abrangente no que se refere às suas dimensões. Uma dessas destaca-se por meio do simbolismo. Esse, como diz Bourdieu (1998), é um instrumento social, o que deixa explícito que não se pode isentar o fator humano da morfologia da paisagem geográfica. Cosgrove (1998, p. 108) contribui com essa discussão, afirmando que as paisagens são constituídas por significados simbólicos “[...] porque são o produto da apropriação e transformação do meio ambiente pelo homem”, que é o protagonista do processo de simbolização.

Ainda em relação às dimensões das paisagens, atenta-se também para as percepções como sendo reveladoras dos sentimentos humanos. Desse modo, vale esclarecer o que é percepção. Uma definição simples e objetiva é a de que percepção é a exteriorização de pensamentos, sentimentos e pontos de vista interiores aos humanos. Do mesmo modo, pode-se dizer que percepção é “[...] a resposta dos sentidos aos estímulos externos [...]" (TUAN, 1980, p. 04). Sendo assim, não é difícil compreender que as percepções decorrem da subjetividade, sendo egocêntricas. Frisa-se que "a subjetividade [...] é um dos traços mais marcantes do humanismo e deriva diretamente [...] [da] concepção antropocêntrica" (GOMES, 1996, p. 310).

Quando se trabalha com percepções, deve-se ter uma abordagem em que o ponto de partida é o conhecimento revelado pelos pontos de vista populares. Esse conhecimento é o "[...] resultado da apreensão da realidade contida em um objeto” (SANTOS, 2004, p. 92). 
Santos (Ibid.), ao refletir sobre as correntes epistemológicas da Geografia, destaca que as percepções foram alvo de estudos na chamada Geografia da Percepção e do Comportamento, colocada em baila, no cenário brasileiro, em meados do século XX. O geógrafo afirma que essa corrente limitou-se a utilizar-se das percepções para apreender o que os objetos apresentam externamente e não o que eles representam sóciohistoricamente. Fazendo isso, a Geografia da Percepção tornou-se nua ideologicamente, isto é, não atentando para o sentido simbólico presente nos objetos.

$\mathrm{Na}$ atualidade, os estudos geográficos que trabalham com percepções seguem a lógica da representatividade. Devem-se considerar as percepções como conhecimentos primeiros que podem revelar, juntamente com o cognitivo, a funcionalidade dos objetos, isto é, os seus simbolismos.

Seguindo essa lógica atual, Santos (2004, p. 94) frisa que “[...] os objetos carregados de significação transmitem esta significação a seus observadores”. Por isso, é mister que nos estudos do sentido simbólico dos objetos se atente para a significação atribuída e para a significação real dada a esses.

Em relação à ciência geográfica, mas não com exclusividade, existem teorias que versam acerca das percepções. Dentre essas, pode-se destacar a de Piaget, a de Gestalt, a de Gibson e a de Tuan. Para conhecê-las e compreender a contribuição dessas teorias para os estudos geográficos, pode-se consultar os trabalhos de Oliveira (2001, 2000 e 1977).

Vemos que, no contexto da Geografia Cultural Renovada, a paisagem ganha novas compreensões. Contudo, não devemos, em hipótese alguma, acreditar que as compreensões acerca da paisagem estejam sendo esgotadas ou aprofundadas demasiadamente. Pelo contrário, o caminho para a compreensão cada vez mais significativa da paisagem está apenas em curso, provavelmente no seu início. É isso que nos ensina Soja (1993, p. 191) quando declara que "a paisagem tem uma textualidade que estamos apenas começando a compreender, pois só recentemente pudemos vê-la por inteiro e lê-la com respeito a seus movimentos mais amplos e seus eventos e sentidos inscritos” (destaque do autor).

As paisagens sob um ponto de vista hermenêutico, isto é, interpretativo vêm sendo estudadas no âmbito da Geografia Cultural Renovada. São estudos que atentam para os significados de lagoas; praças; festas; cidades; monumentos; campos de futebol; famílias detentoras de grande poder; etc.

Em 2007, tornamos público um estudo interpretativo que vínhamos desenvolvendo sobre uma paisagem localizada em Bom Jesus-RN (figura 01), denominada de Lagoa das Panelas. 


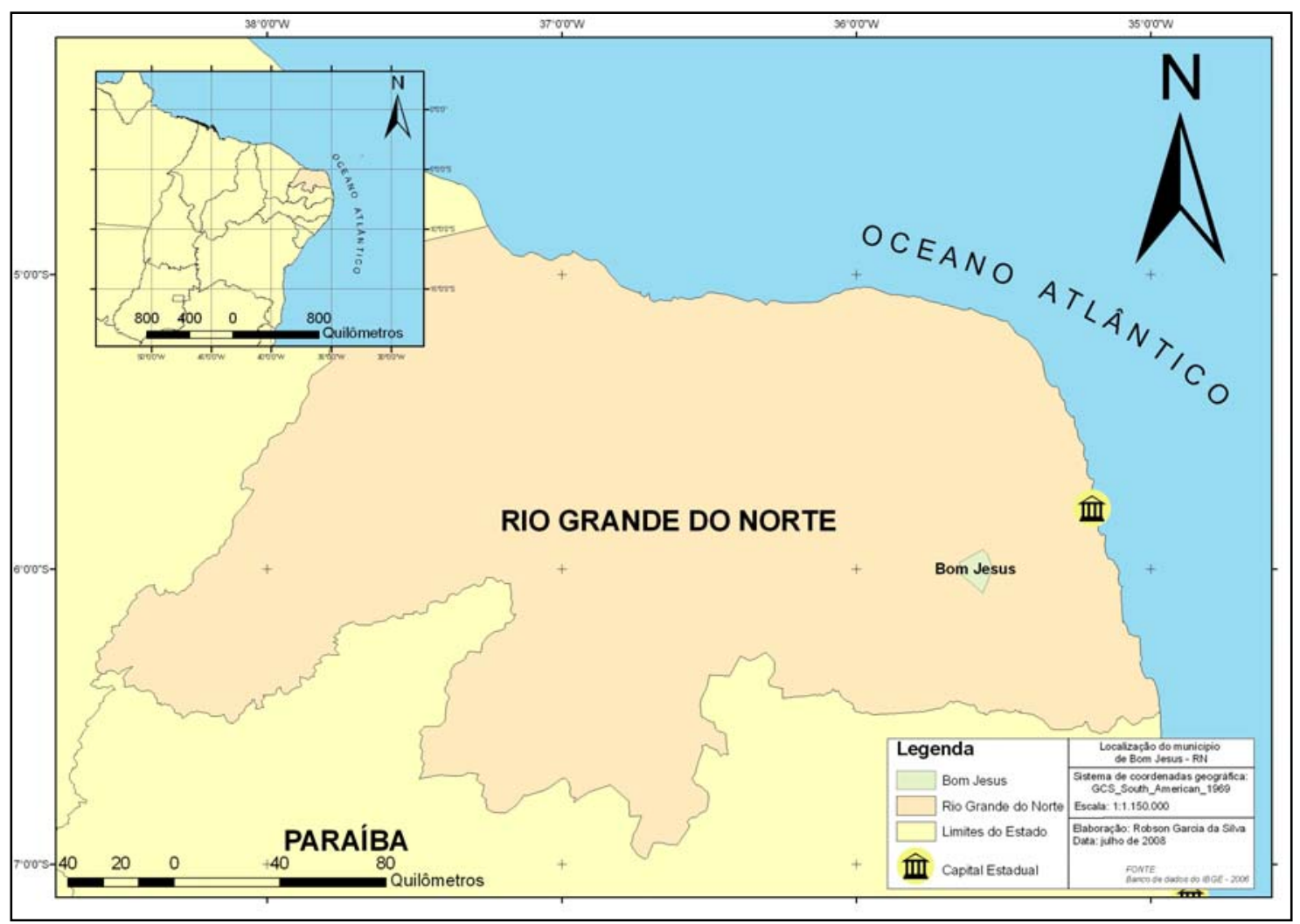

Figura 01: Localização do município de Bom Jesus no âmbito do Rio Grande do Norte Cartografia: Robson Garcia da Silva, 2008.

Através de estudos sobre a formação socioespacial de Bom Jesus, pudemos ter conhecimento da importância da Lagoa das Panelas para esse processo histórico. Podemos, sem meias palavras, declarar e defender que essa lagoa liga-se indissociavelmente à gênese e expansão do município de Bom Jesus (SALVADOR, 2007). A partir desse conhecimento, fizemos uma pesquisa, em 2005, para saber qual era o significado da Lagoa das Panelas para a população bonjesusense. Essa pesquisa revelou que essa lagoa é considerada o símbolo dos bonjesusenses.

Com isso, realizamos estudos sobre a história desse símbolo. Esses estudos colocaram em tela uma situação dramática: a Lagoa das Panelas vem sendo ao longo dos anos destruída pela própria população bonjesusense, por meio de um processo de expansão socioespacial calcado apenas nos interesses econômicos e políticos individuais, negligenciando as dimensões social e ambiental. Em função disso, na atualidade, a Lagoa das Panelas encontra-se em uma situação de graves degradações ambientais. As figuras 02 e 03 mostram como a lagoa foi transformada de maneira predatória pelos bonjesusenses. 


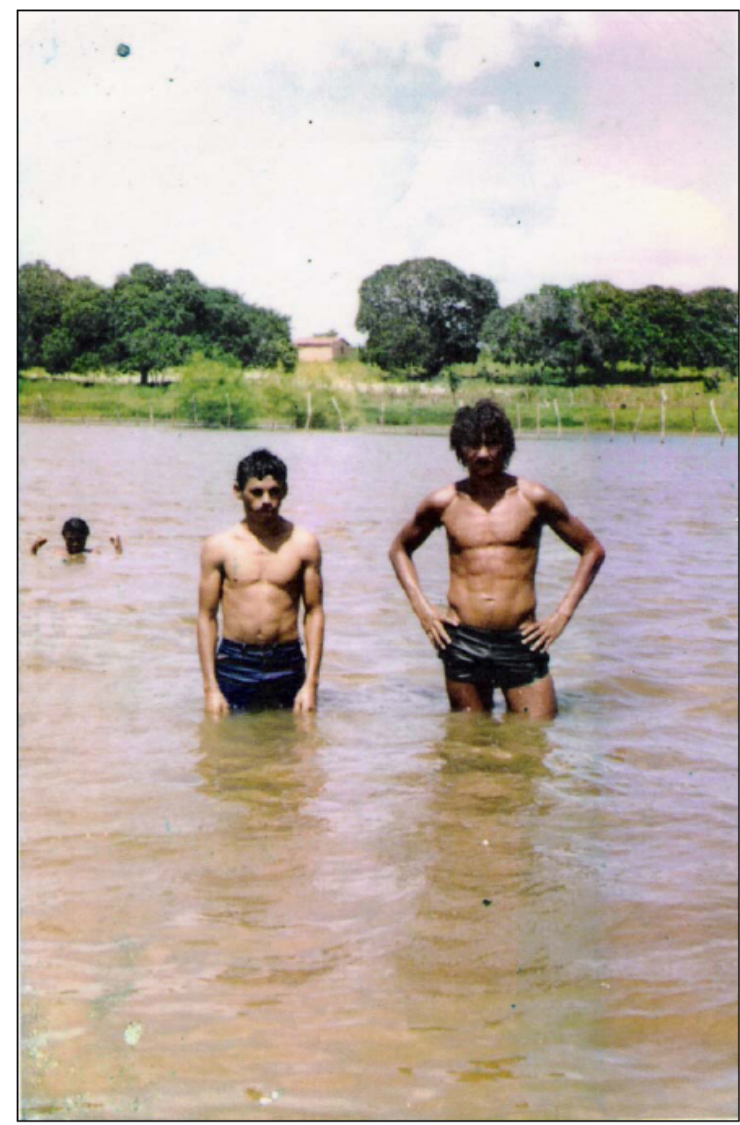

Figura 02: Moradores bonjesusenses divertindo-se na Lagoa das Panelas

Fonte: Silva, 1976.

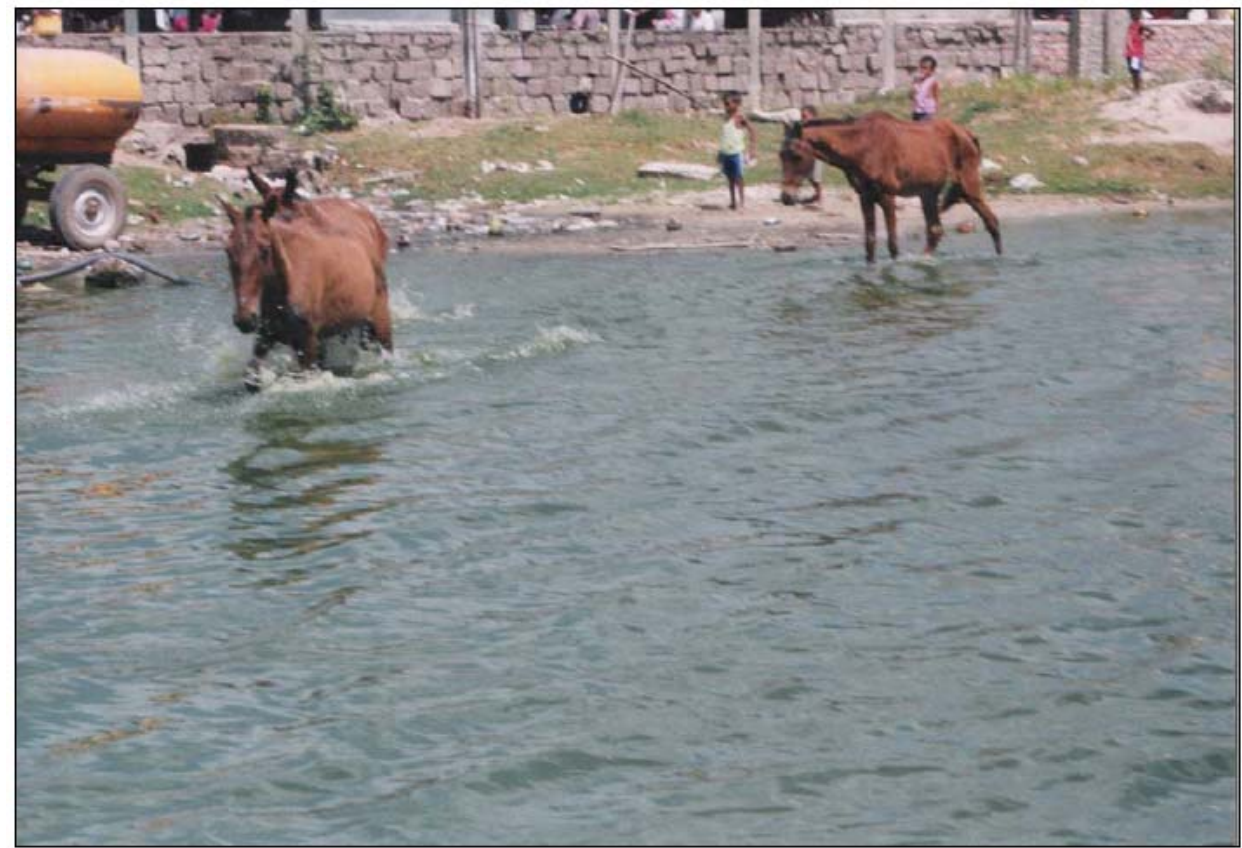

Figura 03: Lagoa das Panelas na atualidade. Animais tomando banho na lagoa, com a presença de crianças no mesmo momento Fonte: Salvador, 1997. 
Com isso, nosso estudo passou a ser alicerçado em um questionamento que expressa a situação contraditória que perpassa a lagoa: por que a Lagoa das Panelas, símbolo dos bonjesusenses, vem sendo degradada? Inquietava-nos o fato de um símbolo estar sendo historicamente degradado pela própria população que o vivencia e lhe atribui valor, significado.

Desse modo, sentimos a necessidade de realizar outra pesquisa, pedindo aos bonjesusenses que expressassem suas percepções acerca da atual situação degradante da lagoa. Essa pesquisa foi feita em 2006 e revelou, basicamente, três vertentes de opiniões sobre a situação atual da lagoa: 1) a Lagoa das Panelas encontra-se degradada por culpa das autoridades políticas locais, que são negligentes para com o símbolo dos bonjesusenses; 2) a culpa é do povo, que por falta de educação ambiental degrada o seu próprio símbolo; e 3) a culpa é de todos, autoridades e povo em geral, que juntos desencadeiam a degradação da Lagoa das Panelas. Nossa opinião é de que a degradação da lagoa é um caso de coresponsabilidades, isto é, desencadeia-se historicamente por meio das ações de todos os bonjesusenses, sem exceções.

Diante de todo esse percurso seguido no estudo sobre a lagoa, passamos a investir na formulação de algumas considerações finais sobre o que refletimos. Primeiro, declaramos que é urgente a tomada de providências coletivas e significativas por parte dos bonjesusenses em relação à Lagoa das Panelas, como forma de evitar a destruição total do símbolo. Além disso, afirmamos que a lagoa pode não ser o símbolo dos bonjesusenses, em função dela estar sendo degradada historicamente por meio das ações dos próprios moradores locais. Dizemos isso por acreditarmos, de acordo com Bourdieu (1998), que um símbolo é aquilo que é cuidado, zelado, pertencido, querido, enfim, protegido e não aquilo que é repudiado, degradado.

Por fim, diz-se que esse estudo sobre a Lagoa das Panelas revela como as paisagens são complexas, devendo ser estudadas de maneira ampla e interpretativa. Cabe a nós geógrafos, assim como a outros cientistas sociais, desencadearmos esses estudos.

\section{REFERÊNCIAS}

ANDRADE, M. C. de. Geografia: ciência da sociedade. Uma introdução à análise do pensamento geográfico. São Paulo: Atlas S.A., 1987.

BERQUE, A. Paisagem-Marca, Paisagem-Matriz: elementos da problemática para uma Geografia Cultural. In: ROSENDAHL, Z.; CORREAA, R. L. Paisagem, tempo e cultura. Rio de Janeiro: EdUERJ, 1998. p. 84-91.

BOBEK, H.; SCHMITHUSEN, J. A paisagem e o sistema lógico da Geografia. In: ROSENDAHL, Z.; CORREAA, R. L. Paisagem, tempo e cultura. Rio de Janeiro: EdUERJ, 1998. p. 75-83.

BOURDIEU, P. O poder simbólico. Tradução de Fernando Tomaz. Rio de Janeiro: Bertrand Brasil, 1998.

CASCUDO, L. da C. Nomes da terra: história, geografia e toponímia do Rio Grande do Norte. Coleção Cultura. Natal: Fundação José Augusto, 1968. 
CHRISTOFOLETTI, A. Impactos no meio ambiente ocasionados pela urbanização no mundo tropical. In: SOUZA, M. A. A. de. (org.) O novo mapa do mundo: natureza e sociedade de hoje, uma leitura geográfica. São Paulo: Hucitec, 1993.

CLAVAL, P. A contribuição francesa ao desenvolvimento da abordagem cultural na Geografia. In: CORRÊA, R. L. ; ROSENDAHL, Z. (orgs.) Introdução à Geografia Cultural. Rio de Janeiro: Bertrand Brasil, 2003. p. 147-166.

A Geografia Cultural. Tradução de Luiz Fugazzola Pimenta e Margareth de Castro Afeche Pimenta. Florianópolis: UFSC, 1999a.

A Geografia Cultural: o estado da arte. In: ROSENDAHL, Z.; CORRÊA, R. L. Manifestações da cultura no espaço. Rio de Janeiro: EdUERJ, 1999b. p. 59-99.

CORRÊA, R. L. ; ROSENDAHL, Z. (org.) A Geografia Cultural e o urbano. In: Introdução à Geografia Cultural. Rio de Janeiro: Bertrand Brasil, 2003.

. (orgs.) Introdução à Geografia Cultural. Rio de Janeiro: Bertrand Brasil, 2003.

Apresentando leituras sobre paisagem, tempo e cultura. In: Paisagem, tempo e cultura. Rio de Janeiro: EdUERJ, 1998. p. 07-11.

Geografia Cultural: um século (1). Rio de Janeiro: EdUERJ, 2000.

CORRÊA, R. L. Geografia Cultural: passado e futuro - uma introdução. In: ROSENDAHL, Z.; CORREAA, R. L. Manifestações da cultura no espaço. Rio de Janeiro: EdUERJ, 1999. p. 49-59.

COSGROVE, D. E. ; JACKSON, P. Novos rumos da Geografia Cultural. Tradução de Márcia Trigueiro. In: CORRÊA, R. L. ; ROSENDAHL, Z. (orgs.) Introdução à Geografia Cultural. Rio de Janeiro: Bertrand Brasil, 2003a. p. 135-146.

COSGROVE, D. A Geografia está em toda parte: cultura e simbolismo nas paisagens humanas. In: ROSENDAHL, Z.; CORREAA, R. L. Paisagem, tempo e cultura. Rio de Janeiro: EdUERJ, 1998. p. 92-123.

Em direção a uma Geografia Cultural Radical: problemas da teoria. Tradução de Olívia B. Lima da Silva. In: CORRÊA, R. L. ; ROSENDAHL, Z. (orgs.) Introdução à Geografia Cultural. Rio de Janeiro: Bertrand Brasil, 2003b. p. 103-134.

Geografia Cultural do Milênio. In: ROSENDAHL, Z.; CORRÊA, R. L. Manifestações da cultura no espaço. Rio de Janeiro: EdUERJ, 1999. p. 17-49.

DUNCAN, J. S. O supra-orgânico na Geografia Cultural Americana. Tradução de Beatriz Juaçaba e Maria Facó. In: CORRÊA, R. L. ; ROSENDAHL, Z. (orgs.) Introdução à Geografia Cultural. Rio de Janeiro: Bertrand Brasil, 2003. p. 63-102. 
GOMES, P. C. da C. Cultura ou civilização: a renovação de um importante debate. In: ROSENDAHL, Z.; CORREAA, R. L. Manifestações da cultura no espaço. Rio de Janeiro: EdUERJ, 1999. p. 99-123.

Geografia e modernidade. Rio de Janeiro: Bertrand Brasil, 1996.

GUIMARÃES, S. T. de. L. Reflexões a respeito da paisagem vivida, topofilia e topofobia à luz dos estudos sobre experiência, percepção e interpretação ambiental. Geosul, Florianópolis, v. 17, n. 33, jan./jun. 2002, p. 117-141.

HAESBAERT, R. Identidades territoriais. In: ROSENDAHL, Z.; CORRÊA, R. L. Manifestações da cultura no espaço. Rio de Janeiro: EdUERJ, 1999. p. 169-191.

HOEFLE, S. W. O futuro da cultura: o espectro do neodarwinismo. In: ROSENDAHL, Z.; CORREAA, R. L. Manifestações da cultura no espaço. Rio de Janeiro: EdUERJ, 1999. p. 123-149.

HOLZER, W. Paisagem, imaginário, identidade: alternativas para o estudo geográfico. In: ROSENDAHL, Z.; CORREAA, R. L. Manifestações da cultura no espaço. Rio de Janeiro: EdUERJ, 1999. p. 149-169.

INSTITUTO BRASILEIRO DE GEOGRAFIA E ESTATÍSTICA. Censo demográfico. Disponível em: <http://www.ibge.gov.br/cidadesat/default.php>. Acesso em: 23 ago. 2005.

INSTITUTO DE DESENVOLVIMENTO ECONÔMICO E MEIO AMBIENTE DO RIO GRANDE DO NORTE. Perfil do seu município: Bom Jesus. Natal, 2005.

MCDOWELL, L. A transformação da Geografia Cultural. In: GREGORY, D. ; MARTIN, R. ; SMITH, G. (org.). Geografia Humana: sociedade, espaço e ciência social. Rio de Janeiro: Jorge Zahar Ed., 1994.

MEINIG, D. W. O olho que observa: dez versões da mesma cena. Espaço e Cultura, UERJ, Rio de Janeiro, n. 13, jan./jun. 2002, p. 35-46.

MONBEIG, P. A paisagem, espelho de uma civilização. In: DANTAS, A. Pierre Monbeig: um marco da Geografia brasileira. Porto Alegre: Sulina, 2005. p. 116-127.

MORAES, A. C. R. Meio ambiente e ciências humanas. São Paulo: Editora Hucitec, 1994.

NÓBREGA, R. T. Bom Jesus: origem e emancipação. 2003. Monografia (Especialização)

- Universidade Federal do Rio Grande do Norte, São Paulo do Potengi.

OLIVEIRA, L. Ainda sobre a percepção. In: A EPISTEMOLOGIA DA GEOGRAFIA CONTEMPORÂNEA FACE AOS DESAFIOS DA SOCIEDADE GLOBAL. I COLÓQUIO NACIONAL DE PÓS-GRADUAÇÃO EM GEOGRAFIA. Textos básicos relativos aos temas das mesas redondas. Curitiba, UFPR, 2001.

de. Contribuição dos estudos cognitivos à percepção geográfica. Geografia, Rio Claro, v. 2, n. 3, abr. 1977, p. 61-72. 
de. Percepção da paisagem geográfica: Piaget, Gibson e Tuan. Geografia, Rio Claro, v. 25, n. 2, ago. 2000, p. 05-22.

PIAGET, J. ; INHELDER, B. A representação do espaço na criança. Tradução de Bernardina Machado de Albuquerque. Porto Alegre: Artes Médicas, 1993.

RELPH, E. C. As bases fenomenológicas da Geografia. Banco de dados do Departamento de Geografia da Universidade Federal do Rio Grande do Norte. Registro n. 1411. Natal, 1988. p. 01-25.

RIBEIRO, J. C. Memória, espaço e imaginário: rememorando espaços passados e projetando espaços futuros. Formação, Presidente Prudente, n. 8, 2001, p. 141-156.

ROSENDAHL, Z.; CORRÊA, R. L. Manifestações da cultura no espaço. Rio de Janeiro: EdUERJ, 1999.

Paisagem, tempo e cultura. Rio de Janeiro: EdUERJ, 1998.

SALVADOR, D. S. C. de O. Paisagem geográfica, simbolismo e degradações ambientais: estudo sobre a Lagoa das Panelas em Bom Jesus-RN. 2007. Monografia (Licenciatura em Geografia) - CEFET-RN, Natal.

SANTOS, M. A natureza do espaço: técnica e tempo, razão e emoção. São Paulo: Hucitec, 1999.

Metamorfoses do espaço habitado: fundamentos teóricos e metodológicos da Geografia. São Paulo: Hucitec, 1994.

Por uma Geografia Nova: da crítica da Geografia a uma Geografia Crítica. São Paulo: Editora da Universidade de São Paulo, 2004.

SAQUET [e outros], M. A. Paisagem, espaço e território. Formação: conceitos geográficos, Presidente Prudente, v. 1, n. 11, UNESP, 2004.

SAUER, C. O. A morfologia da paisagem. In: ROSENDAHL, Z. ; CORRÊA, R. L. Paisagem, tempo e cultura. Rio de Janeiro: EdUERJ, 1998. p. 12-74.

- Geografia Cultural. Tradução de Susana Mara Miranda Pacheco e Zeny Rosendahl. Publicação original em 1962. In: CORREAA, R. L. ; ROSENDAHL, Z. (orgs.) Introdução à Geografia Cultural. Rio de Janeiro: Bertrand Brasil, 2003. p. 19-26.

SOJA, E. W. Geografias Pós-Modernas: a reafirmação do espaço na teoria social crítica. Tradução de Vera Ribeiro. Revisão técnica de Bertha Becker e Lia Machado. Rio de Janeiro: Jorge Zahar Editor, 1993.

THIOLLENT, M. Metodologia da pesquisa-ação. São Paulo: Cortez, 1994.

TUAN, Yi-Fu. Espaço e lugar: a perspectiva da experiência. São Paulo: Difel, 1983. 
Topofilia: um estudo de percepção, atitudes e valores do meio ambiente. São Paulo: Difel, 1980.

WAGNER, P. L. ; MIKESELL, M. W. Os temas da Geografia Cultural. Tradução de Olívia de Barros Lima da Silva. Revisão de Roberto Lobato Corrêa. In: CORRÊA, R. L. ; ROSENDAHL, Z. (orgs.) Introdução à Geografia Cultural. Rio de Janeiro: Bertrand Brasil, 2003. p. 27-61. 